\title{
Should Agents Be Immodest?
}

Marc-Kevin Daoust, Harvard University (․ㅣk.daoust@live.ca)

Forthcoming in Analytic Philosophy. DOI: 10.1111/phib.12194

\begin{abstract}
Epistemically immodest agents take their own epistemic standards to be among the most truth-conducive ones available to them. Many philosophers have argued that immodesty is epistemically required of agents, notably because being modest entails a problematic kind of incoherence or self-distrust. In this paper, I argue that modesty is epistemically permitted in some social contexts. I focus on social contexts where agents with limited cognitive capacities cooperate with each other (like juries).
\end{abstract}

Keywords: Immodesty, social epistemology, epistemic labour, fallibilism, Condorcet's Jury Theorem

Imagine an extremely confident businessman. He thinks he makes the best deals, plans and decisions. When others disagree with his decisions, he simply assumes that they are less competent than him. What would you think of him? Surely, you won't think that he is modest - that is, you won't think that he is moderated in estimating his own abilities and success. Also, you might be inclined to criticize him for lacking modesty.

Most ethicists have the same intuitive reaction. They think that immodesty is pro tanto bad or vicious. ${ }^{1}$ Interestingly, epistemologists are much more inclined to think of immodesty in positive terms. From an epistemic point of view, immodest agents take their own standards to be among the most truth-conducive ones that are available to them. Many epistemologists have argued that immodesty is epistemically required of agents. Specifically, it has been argued that maintaining standards that agents take to be suboptimal entails a problematic kind of incoherence or self-distrust. If agents believe that other standards are more truth-conducive than theirs, they should think that it is best for them to revise their own standards. In view of the foregoing, modesty seems epistemically impermissible.

1 See Bommarito (2018) for an overview of this debate in ethics. See Roush (2017) on related debates in the epistemic realm. 
In this paper, I argue that the requirement of immodesty faces a challenge in social contexts. Roughly, the argument goes as follows. We are fallible agents with limited cognitive capacities. One way to go beyond our limited cognitive capacities is to cooperate with each other in epistemic groups or institutions. We trust some of these institutions more than we trust ourselves - that is, we take the institutional standards to be more reliable than our own individual standards. Yet these institutions are epistemically successful because we entertain our individual standards. So, we find ourselves in an odd position: the institutional standards are better than ours insofar as we maintain our own, suboptimal individual standards. I argue that, in such contexts, agents are epistemically permitted to be modest.

To be clear: this paper belongs to the field of "de-idealized" epistemology or bounded rationality. ${ }^{2}$ As I just said, I am here concerned with fallible agents with limited cognitive capacities. For instance, I indicate in section 2 that, if entertaining standard $\mathrm{X}$ is too cognitively demanding of agents, they are epistemically permitted not to entertain standard X. So, perhaps ideal agents with unlimited cognitive capacities are required to be immodest. My argument merely says that, when it comes to de-idealized epistemic norms, there are counterexamples to immodesty.

\section{Immodest Agents, Standards and Methods}

In order to be coherent, agents ought to refrain from having some combinations of beliefs. Incoherence can be understood in a narrow, logical sense-for instance, believing P and disbelieving P simultaneously is logically inconsistent. ${ }^{3}$ However, incoherence captures a broader range of combinations of beliefs - for instance, combinations of beliefs such as "P, but it is irrational for me to believe P" or "P, but I don't believe P" are incoherent without necessarily displaying logical inconsistency. ${ }^{4}$ The requirement of immodesty is a

2 See Daoust (2019) on why the point I am making might not generalize to ideal agents.

3 See Broome (2013, sec. 9.2) on consistency. Some philosophers also endorse an Intra-Level Coherence principle, which roughly states that if A believes that $P_{1}$, believes that $P_{2}, \ldots$ and believes that $P_{n}$, then it is false that A believes that $\sim\left(\mathrm{P}_{1} \wedge \mathrm{P}_{2} \ldots{ }^{\wedge} \mathrm{P}_{\mathrm{n}}\right)$. See Clarke (2013) and Leitgeb (2014a; 2014b) on Intra-Level Coherence. However, some solutions to the Lottery Paradox entail that Intra-Level Coherence is not a genuine requirement of epistemic rationality. See notably Demey (2013), Foley (2009) and Sturgeon (2008).

4 See Coates $(2012)$ and Lasonen-Aarnio $(2014 ; 2015 ; 2018)$ on epistemically akratic combinations of beliefs. See also Greco (2014), Horowitz (2014a), Kiesewetter (2016), Littlejohn (2015), Titelbaum 
requirement of coherence in the broad sense. It governs the relationship between an agent's possessed epistemic standards and his or her beliefs concerning such standards.

What does it mean to possess an epistemic standard? Li (2016) argues that a necessary condition for possessing a standard is that there must be some sort of explanatory connection (or at least correlation) between how agents reason and their standards. This is the Applicability Criterion. ${ }^{5}$ Accordingly, I will assume that an agent's possesses epistemic standards $\mathrm{S}$ if $\mathrm{S}$ are the rules, models or assumptions he or she relies on to evaluate the evidence (or if $\mathrm{S}$ are the rules he or she is disposed to rely on). ${ }^{6}$ They act as functions mapping an agent's evidence onto doxastic attitudes towards P.

I take this to be a common interpretation of what it means to possess a standard. Suppose that, when Paul comes to learn that the Chief Doctor said that $\mathrm{P}$, he forms the belief that $\mathrm{P}$. Then, there is an ordinary sense in which we can say that he possesses the standard: "Believe what the Chief Doctor says." However, this account of standard possession is fairly weak. Some philosophers might think that there are more conditions on possessing a standard, like fully supporting the standard, or something similar. ${ }^{7}$ Those who endorse a different account of standard possession can conditionalize the rest of my argument on the assumption that the weak account of standard possession is correct. ${ }^{8}$

Now, what is incoherent about modesty? It is incoherent for agents to endorse some standards while thinking that other standards available to them are epistemically superior.

(2015) and Worsnip (2018) for replies. See Chislenko (2014), Huemer (2007) and Smithies (2012) on moore-paradoxical combinations of beliefs.

$5 \mathrm{Li}(2016$, sec. 4.2) also thinks that, in cases where a rational agent has rational standards, the theory of standard possession should explain why agents ought to form beliefs in accordance with their own standards, rather than with other standards. This is his Normative Criterion. However, this criterion primarily applies to theories of standard possession that are trying to avoid the arbitrariness objection. The objection from arbitrariness roughly says that, if there were incompatible but (fully) rational epistemic standards available to agents, then they could arbitrarily switch between distinct standards, which seems problematic. Some authors (like Schoenfield 2014) try to avoid this objection, and endorse something like the Normative Criterion. I will not take a stand on whether arbitrariness is epistemically problematic. Accordingly, I here leave aside Li's second criterion.

6 The formulation in terms of dispositions allows for performance errors (e.g., cases in which an agent has a rule for evaluating the evidence, but does not apply it correctly). See Li (2016, sec. 6).

7 For instance, see note 5 for discussion of an additional criterion on standard possession.

8 In any case, even if my account of standard possession raises some concerns, we will have learned something interesting on whether agents should be Immodest. That is, those who wish to save Immodesty for non-ideal agents must accept a strong interpretation to standard possession. 
After all, if one thinks that some standards are epistemically superior, one should feel some pressure to take those standards. Entertaining standards that one takes to be less than optimal entails some sort of incoherence or self-distrust. In view of the foregoing, many philosophers think that legitimate epistemic standards are immodest, or that agents are epistemically required to be immodest. ${ }^{9}$ Relatedly, many recent philosophical arguments presuppose that agents are epistemically required to be immodest. ${ }^{10}$

Different definitions of immodesty have been offered. The most popular version goes as follows:

Immodesty (initial). Relative to their evidence, agents take their own doxastic states (i.e. beliefs and credences) to be the most accurate ones and they take their own epistemic standards to be the most truth-conducive ones. ${ }^{11}$

Here is the one I favour:

Immodesty. Relative to their evidence, agents take their own epistemic standards to be among the most truth-conducive ones that are available to them.

First, as indicated earlier, I here focus on epistemic standards. I leave aside immodesty for doxastic states. Surely, there is something wrong with combinations of beliefs such as: "I believe $P$, but believing $\sim P$ would be more accurate." However, we can

9 Lewis $(1971,56)$ (and Elga 2010) suggests that modest methods or standards cannot be completely trusted, and thus display a kind of internal failure. See also Hedden (2015), Horowitz (2014b) and Schoenfield (2014). Other philosophers reject immodesty. Christensen (2013) argues that epistemic modesty can be permitted in cases where various epistemic ideals (e.g., ideals of coherence, good reasoning and evidence-responsiveness) conflict with each other. Relatedly, DiPaolo (2018) argues that, in non-ideal contexts where various epistemic norms conflict with each other, modesty can be part of an epistemic second-best (e.g., the best non-ideal option available to agents). Belot (2013) addresses a related problem in a Bayesian context. Roughly, Belot doubts that agents should be immodest in cases where it is almost certain that no method or standard is accurate. See Weatherson (2015) for discussion. Mayo-Wilson and Wheeler (2016) argue that, in order to accommodate scoring rules for imprecise credences, immodesty ought to be replaced with a weaker principle.

10 Hedden $(2015,720-21)$ argues that the fundamental facts about evidential support must be a priori. According to him, the immodesty criterion provides support for objectivism, because immodest methods treat themselves as empirically indefeasible. Horowitz (2014b) argues that immodesty precludes permissivism, the view roughly stating that, relative to a body of evidence agents are sometimes permitted to entertain distinct incompatible doxastic attitudes towards P. By way of contrast, Schoenfield (2014) also thinks that immodesty is correct, but argues that it is compatible with interpersonal permissivism. See Li $(2016,9-10)$ for a reply to Schoenfield's argument.

11 As in Lewis $(1971,55)$ and Schoenfield $(2014,201-2)$, notably. We could also specify what "most truthconducive" means exactly. For instance, we could assign an epistemic value $\mathrm{T}$ to having a true belief in $\mathrm{P}$ and an epistemic disvalue $\mathrm{F}$ to having a false belief in $\mathrm{P}$, and say that most truth-conducive standards maximize epistemic value (or expected epistemic value). But there is no need to be that specific here. 
explain why such combinations of beliefs are problematic or prohibited without referring to Immodesty. If one thinks that believing $\sim \mathrm{P}$ would be more accurate than believing $\mathrm{P}$, one thinks that $\mathrm{P}$ is false. So, being modest concerning one's doxastic states roughly amounts to having Moore-paradoxical beliefs, such as "P is false, but I believe P." 12 Thinkers with such beliefs seem to contradict themselves. Thus, agents who believe $\mathrm{P}$ while thinking that believing $\sim \mathrm{P}$ would be more accurate violate other requirements than Immodesty (such as requirements prohibiting Moore-paradoxical beliefs).

By way of contrast, thinking that one's standards are less truth-conducive than others does not amount to having Moore-paradoxical beliefs. Agent might know that their standards are suboptimal without also knowing which of their beliefs are less accurate. Suppose you and $\mathrm{I}$ have the same evidence. We take a test on our beliefs in $\left\{\mathrm{P}_{1}, \mathrm{P}_{2} \ldots, \mathrm{P}_{\mathrm{n}}\right\}$ and are informed of the results. I got $80 \%$ on the test, while you got $90 \%$. Provided that I trust the results, this is good evidence that your standards are more truth-conducive than mine. Still, all I know is that you have a better ratio of true to false beliefs in $\left\{\mathrm{P}_{1}, \mathrm{P}_{2} \ldots, \mathrm{P}_{\mathrm{n}}\right\}$. I don't know what you believe. So, I might continue believing that each particular answer I gave on the test is the most accurate one-that is, I won't come to the conclusion that my belief that $\mathrm{P}_{\mathrm{i}}$ is less accurate than believing $\sim \mathrm{P}_{\mathrm{i}}$. In view of the foregoing, thinking that one's standards are suboptimal can't be reduced to having Moore-paradoxical beliefs. At first sight, modesty concerning epistemic standards doesn't seem reducible to other types of incoherence.

Second, against David Lewis, I here assume that immodest agents take their standards to be among the most truth-conducive ones (and not to be the most truthconducive ones). Here is why. Lewis offers the following argument against modesty:

Suppose you did trust some non-immodest method. By definition, it estimates some competing method to be more accurate than itself. So if you really did trust your original method, you should take its advice and transfer your trust to one of the competing methods it recommends. It is as if Consumer Bulletin were to advise you that Consumer Reports was a best buy whereas Consumer

12 Objection: if one thinks that believing $\sim \mathrm{P}$ is more accurate than believing $\mathrm{P}$, one does not necessarily believe that $\mathrm{P}$ is false. One could simply think that $\sim \mathrm{P}$ is more likely than $\mathrm{P}$. Reply: one then has combinations of beliefs such as " $\sim \mathrm{P}$ is more likely than $\mathrm{P}$, but I believe P." This combination of beliefs is Moore-paradoxical in spirit (Hájek 2007). 
Bulletin itself was not acceptable; you could not possibly trust Consumer Bulletin completely thereafter. (Lewis 1971, 56)

According to Lewis, modesty and non-immodesty are the same thing, and agents who entertain non-immodest standards estimate that other standards are more truth-conducive. However, this doesn't entail that immodest agents take their standards to be the most truthconducive ones. Immodest agents can estimate that there is more than one optimal set of standards. In other words, there could be distinct but equally optimal standards available to agents. ${ }^{13}$ So, the argument put forth by Lewis merely entails that agents should take their standards to be part of the best ones available.

Compare: Buridan's ass is facing two equally good stacks of hay (and he knows they are equally good). Standard Left says "choose the stack of hay on the left," while standard Right says "choose the stack of hay on the right." Suppose he is practically immodest - say, he thinks that the decisions resulting from his practical standards are among the best ones available. Yet, his standards do not necessarily preclude the possibility that other standards are equally optimal. Buridan's ass can entertain standard Left while thinking that standard Right is also optimal. In fact, given what he knows, Buridan's ass is fully aware that both standards are equally optimal. Thus, Immodesty should be neutral on whether optimal options are uniquely determined or not.

Third, following Horowitz (2014b, 43), I here assume that optimality is relative to the options available to agents. Surely, agents can believe that other standards or methods are more truth-conducive than theirs, such as "ignore misleading evidence." However, agents are not always in a position to know when the evidence is misleading. So, they can't take such a standard because it is unavailable to them. Yet agents can be immodest with respect to the standards available to them. ${ }^{14}$ So, Immodesty should be limited to standards that agents can, in fact, satisfy.

13 See Daoust and Montminy (m.s.) for more details.

14 Relatedly, an agent's evidence can constrain the standards available to him or her. Information scientists can learn how to design better algorithms to process the data. Thus, after acquiring new evidence, some better standards will become available to them. Lewis $(1971,55)$ makes similar remarks. 
One final remark: My objection against Immodesty relies on full beliefs (and standards governing their formation and revision). Most philosophers interested in Immodesty are concerned with credences, not full beliefs. Accordingly, one might object that Immodesty is a coherence requirement for credences, not for full beliefs, and so that I am missing the target. I don't think that's right. If the argument put forth by Lewis were conclusive, it would not merely apply to credences. His argument roughly states that thinking that one's doxastic states are suboptimal entails a problematic kind of incoherence. The argument doesn't presuppose that “doxastic states” means credences. In other words, the fact that Lewis was thinking of credences has no bearing on the argument. If Lewis's argument succeeds, Immodesty should govern full beliefs as well.

\section{Should Agents be Immodest? Social Contexts and Opaque Standards}

I will now cast doubt on the claim that agents should be immodest - that is, agents are sometimes epistemically permitted to entertain epistemic standards that they take to be less truth-conducive than other available ones. I believe that important objections against Immodesty come from the way epistemic institutions work. Accordingly, my argument against Immodesty will rely on the division of epistemic labour in some social contexts. It runs as follows:

P1. In social contexts, the individual standards entertained by agents can give rise to available but opaque metastandards.

P2. Such opaque metastandards can be more truth-conducive than the individual standards entertained by agents.

$\mathrm{P} 3$. If $\mathrm{P} 1$ and $\mathrm{P} 2$ are correct, then Immodesty is not epistemically required.

C. So, Immodesty is not epistemically required.

\subsection{Defending $P 1$}

I will give an example of a social context in which agents with individual standards can cooperate with each other and give rise to an available but opaque metastandard. An 
opaque standard is one that agents find difficult to internalize. Yet the standard can be available, in the sense that agents can rely on it to evaluate the evidence (think of artificial neural networks: we can rely on them to shed light on a problem, but it is difficult to know how they work).

Agents like us have limited cognitive capacities and don't reason perfectly. Accordingly, when it comes to making decisions on complex problems, agents must spend a lot of time and energy to think about the various moving parts of the problem and are prone to errors. In an epistemic community, an efficient way to overcome these challenges is to cooperate with each other. This can take many forms. For instance, agents can divide the epistemic labour of collecting evidence, reasoning, and drawing conclusions among members of an epistemic community. Agents can also act as epistemic safeguards for reliable knowledge (think of mechanisms such as peer review —an editor might ask different referees to review a paper, so that their biases are counterbalanced).

Juries are among the most familiar cooperation mechanisms. During complex trials, a single juror is likely to overestimate (or underestimate) the evidence for believing P. However, different jurors with different standards of reasoning working together can minimize such overestimation (or underestimation) biases. Hence, this kind of mechanism can be beneficial in view of making the right decisions.

With these remarks in mind, consider the following case:

Permanent Jury. A jury composed of 99 agents is formed for several trials. Agent 1 entertains standard 1, agent 2 entertains standard 2, and so forth. The individual standards entertained by the jurors are distinct and incompatible with each other. ${ }^{15}$ Given the evidence the jurors acquire during the trials, they ought to determine if the defendants are guilty. The trials are subject to three rules. First, all jurors are presented with the same evidence and they ought to vote on the basis of the shared evidence only. Second, the jurors do not discuss with each other before or after casting their vote. Third, the jurors are faced with a binary choice (such as "Guilty" or "Not Guilty").

In Permanent Jury, the group under simple majority gives rise to a metastandard. In a nutshell, the metastandard says that, relative to a body of evidence, one should believe P (or $\sim \mathrm{P}$ ) if and only if a majority of individual standards recommend believing $\mathrm{P}$ (or $\sim \mathrm{P}$ ). Since

15 See Titelbaum and Kopec (forthcoming, 14) on distinct, incompatible epistemic standards. 
those standards are entertained by jurors, the metastandard could also be formulated as follows: relative to a body of evidence, if a majority of jurors vote for $\mathrm{P}$, one should believe $\mathrm{P}$, and if a majority of jurors vote for $\sim \mathrm{P}$, one should disbelieve $\mathrm{P}$. This metastandard supervenes on the standards entertained by each individual juror, which partly confirms P1. ${ }^{16}$

Assume that jurors know the standards entertained by each other. Accordingly, the

jurors could reconstruct the metastandard and internalize it. Still, it would be difficult for them to internalize it. For instance, suppose a juror needs five minutes to determine if, relative to a body of evidence, an individual standard supports the conclusion that $\mathrm{P}$. Now, since there are 99 individual standards, it would take a juror 495 minutes (and too much mental energy) to determine what the metastandard supports. So, the metastandard is opaque because it is difficult for agents to internalize it. Thus, P1 is true.

\subsection{Defending $P 2$}

P2 follows from well-known results in collective judgment aggregation.

Condorcet's Jury Theorem roughly states that, when equally reliable voters make a choice between two outcomes (such as "guilty" and "not guilty"), the majority rule can lead them to make collective decisions "with a competence that approaches 1 (infallibility) as either the size of the group or the individual competence goes up" (Estlund 1994, 131). A consequence of the Theorem is that a group of jurors under simple majority outperforms the individual competence of each juror. ${ }^{17}$ Both conclusions are correct if three conditions are satisfied. First, the probability that juror $i$ gets the right answer $\left(\operatorname{Pr}_{\mathrm{i}}\right)$ satisfies the following: $0.5<\operatorname{Pr}_{\mathrm{i}}<1$ and $\operatorname{Pr}_{1}=\operatorname{Pr}_{2} \ldots=\operatorname{Pr}_{99}$. Second, the probability that a juror gets the right answer is independent of the probability of any other juror getting the right answer. Third, the jurors are faced with a binary choice (such as "Guilty" and "Not guilty").

The Theorem can be used in favour of P2. Suppose that, in Permanent Jury, the members of the jury are told by a trustworthy informant that each of them reaches the right

16 See Daoust (2019).

17 See Condorcet (1976 [1785]). 
answer $90 \%$ of the time (and assume this is a fact). The jurors are familiar with Condorcet's Jury Theorem (it was part of their jury training). They know that the Theorem's conditions stated above are satisfied. ${ }^{18}$ So, they can deduce that the jury is more reliable than each individual juror. Specifically, they can deduce that the jury under simple majority reaches the right answer $\approx 99.99 \%$ of the time. Since $99.99 \%>90 \%$, the metastandard is more truthconducive than the non-opaque standards available to agents. This confirms P2.

\subsection{Defending $P 3$}

I will now argue that, in cases where P1 and P2 are satisfied, members of a jury are permitted to be modest (e.g., they can entertain an epistemic standard while thinking that a better standard is available to them).

When the jury's verdict is revealed, jurors can update their beliefs on this new piece of information. This is so, because jurors take the jury to be more reliable than each individual juror. So, if they come to know that the jury reached the conclusion that $\mathrm{P}$, they may defer to the jury and believe P. For some jurors, this will mean changing their belief concerning $\mathrm{P}$.

Note that this is not necessarily a sign of modesty. Agents need not to be modest in order to defer to juries. Jurors can treat the jury as an "expert", and deferring to experts can be immodest. Compare: if a doctor runs various tests and comes to a conclusion about your health, deferring to him or her can be part of your optimal epistemic standards.

Now, suppose there is a sufficiently long period of time between (i) the moment when jurors cast their votes and (ii) the moment when the verdict is publicly revealed. In the meantime (i.e., between jurors voting and jurors coming to know the verdict), what should jurors do? During this period of time, jurors are not in a position to defer to the verdict, because it has not been revealed publicly. Yet, they could work out what the

18 The first condition is satisfied, since all the jurors reach the right answer $90 \%$ of the time. The remaining two conditions are mentioned in the description of Permanent Jury. It could be argued that the independence condition is merely satisfied in part since agents have the same evidence. In response to such a worry, we could use a relaxed independence condition that is compatible with the fact that voters have the same evidence (such as Dietrich and List's (2004, 182) Independence Given the Evidence condition or Dietrich and Spiekermann's (2013, sect. 4) New Independence condition). This small adjustment would not affect my argument. For simplicity, I ignore this complication here. 
collective judgment will be. They know the standards entertained by their colleagues on the jury, and they share all the relevant evidence. So, they could guess what the result will be. If jurors processed the evidence through 99 different standards and determined what a majority of standards supports, they would come to know the final verdict before it is publicly revealed.

The fact that jurors can do this puts them in a puzzling position. Suppose Nicolas is a juror in Permanent Jury. Given what I have said previously, he is in a position to conclude that the metastandard is more reliable than his own individual standards. Indeed, if Nicolas estimates that the other jurors reach the right answer more than $\sim 55 \%$ of the time, he should also think that the metastandard is more reliable than his. ${ }^{19}$ As I indicated in section 2.2, Nicolas is told by a trustworthy informant that the jurors reach the right answer at least $90 \%$ of the time. Moreover, it is a fact that each juror reaches the right answer $90 \%$ of the time. So, Nicolas is in a position to know that other jurors are minimally reliable, and he can't reasonably conclude that his individual standards are among the most truth-conducive ones available - in fact, he should come to know that his individual standards are suboptimal.

After realizing that their individual standards are suboptimal, jurors like Nicolas can react in three different ways:

(i) They can go skeptical and cease entertaining their standards;

(ii) They can maintain their individual standards and be modest;

(iii) They can internalize the metastandard.

(i) would have bad consequences. Going skeptical means that Nicolas loses fairly reliable individual standards. Also, recall that the metastandard supervenes on the individual standards entertained by the jurors. So, if the jurors cease entertaining their individual standards, they can't form a functional jury with a highly reliable metastandard. For these reasons, (i) is a bad option.

(iii) is too demanding, since the metastandard is opaque. Jurors know each other's individual standards. So, internalizing the metastandard would be possible, but very

19 This is a consequence of familiar probability rules. 
demanding. Jurors like Nicolas would have to mediate the evidence through 99 standards before being in a position to know what the metastandard recommends. Their mental economy would greatly suffer from internalizing the metastandard. Hence, (iii) is not a good option.

In view of the foregoing, it is more appropriate for jurors like Nicolas to maintain their individual standards. This leaves us with (ii). Following this option, Nicolas is contributing to the metastandard by entertaining his individual standards. He knows that, since jurors like him entertain fairly reliable standards, the group under simple majority is highly reliable. This institutional arrangement is advantageous to everyone and adapted to the non-ideal capacities of the jurors. These considerations can motivate Nicolas to maintain standards that he knows to be suboptimal. In view of the foregoing, (ii) seems like the best option.

Yet, this means that Nicolas should be modest. For instance, while Nicolas maintains his individual standards, he defers to the group's verdicts when they conflict with his own conclusions. This is so, because he takes the group's verdict to be better than his own. Relatedly, if someone asks Nicolas which standard is epistemically optimal, Nicolas will respond: "the metastandard is more reliable than the standards I entertain." This is precisely what a modest agent would respond.

Jurors like Nicolas find themselves in an odd position: the metastandard exists because jurors maintain their own, suboptimal individual standards. Note, however, that this odd result is somehow expected. Indeed, a reason why agents form juries is precisely to give rise to such better standards. This arrangement allows them to achieve more than they could achieve individually. As Buchak and Pettit indicate, "when people organize themselves as a group agent, they generally do so with a view to achieving purposes that are unavailable to them individually" (Buchak and Pettit 2015, 220). In other words, the jurors want to give rise to a standard that is better than theirs, without necessarily being able (or wanting) to internalize such a standard. In such a context, it should come at no surprise that jurors are modest. Reliable institutions like juries come at the price of modest jurors. The trade-off is worth it. 
In sum, since (ii) is the most reasonable option, a juror like Nicolas is permitted to be modest. Given his limited capacities and the opacity of the metastandard, being modest seems like the appropriate stand to take towards his own standards. Of course, if we were concerned with ideal agents who have unlimited cognitive capacities, the problem would solve itself. But we are not, and this is why non-ideal agents are permitted to be modest.

\subsection{What Is the Social Dimension of the Argument?}

One could object that my argument has nothing to do with the division of epistemic labour in social institutions. It merely has to do with the fact that internalizing some standards is too demanding, and agents are epistemically permitted not to take standards that are too demanding. So, the social aspect of the problem is irrelevant: the reason why Nicolas is epistemically permitted not to take the metastandard is that this would be too demanding.

My response to this worry is that, if Nicolas were not taking part in a social institution like a jury, there would be more reasons for him to take the most truth-conducive standards available to him. To see why, consider the following case:

Desert Island. Nicolas is on a desert island. He wonders whether P. In order to determine whether $\mathrm{P}$ is the case, two belief-forming methods are available to him, namely, A and B. Method A is $99 \%$ reliable, but mentally taxing. It would take Nicolas one week to process the evidence with $\mathrm{A}$, which would affect his mental economy. By contrast, $\mathrm{B}$ is a fast and frugal heuristic. It would take him 10 seconds to process the evidence with method B. Yet this method is $90 \%$ reliable.

There is an important difference between the jury case and Desert Island. In a social context like a jury, Nicolas knows that, after some time, he will know what the metastandard supports. The jury's verdict will be known publicly after some time. So, Nicolas can believe in accordance with the maximally reliable belief-forming method. $\mathrm{He}$ simply has to wait until the verdict is publicly revealed. This is why internalizing the metastandard would be such a waste of his time and mental resources.

However, on Desert Island, Nicolas doesn't have the option to wait until he knows what the most reliable standard supports. On Desert Island, the only way to know what the 
most reliable belief-forming method (A) supports is to process the evidence with such a method. So, when one is on a desert island and one wants to believe in accordance with the most truth-conducive standards, one has to process the evidence through the most truthconducive standards. In other words, in Desert Island, Nicolas has no easy and efficient way to believe in accordance with the most truth-conducive methods available to him. This puts more pressure on agents in Desert Island to process the evidence in accordance with the most truth-conducive standards.

This is why social contexts matter. Communities can be highly reliable without forcing individuals in such communities to entertain the maximally reliable standards available to them. By contrast, isolated individuals do not have this option. Hence, the division of epistemic labour in social institutions matters. ${ }^{20}$

Here is another way to put it. There are putative objections against Immodesty that have nothing to do with social mechanisms. For instance, some philosophers have argued that we should make a distinction between the epistemically required and the epistemically supererogatory (Jackson forthcoming, 5-7; Li 2017). Suppose agents ought to entertain sufficiently reliable standards, but not maximally reliable standards. Accordingly, agents could believe that their own standards are suboptimal because they merely do what is required of them. They could know that better standards are available to them, but since they do not want to be epistemic heroes, they nevertheless choose to maintain standards they take to be suboptimal.

This tentative objection against Immodesty is relevant. Yet, some epistemic consequentialists could offer the following reply: "Epistemic norms aim at optimizing truth-conduciveness. If you want to optimize your ratio of true to false beliefs, you have to be an epistemic hero. There is no way around it." I think that a social perspective on epistemic norms allow us to see why this kind of reply is mistaken. In social contexts, we can optimize truth-conduciveness without taking over-demanding individual standards. Jurors have access to an undemanding method for optimizing collective reliability. In other

20 I thank a referee for inviting me to discuss this objection. 
words, truth-conducive social mechanisms alleviate the pressure agents face to be epistemic heroes.

\subsection{The Objection From Insincerity}

Here is an objection to my argument. After realizing that their individual standards are suboptimal, jurors like Nicolas can go skeptical and cease entertaining their standards. I have argued that this would have bad consequences, since the jury cannot function if jurors lack individual standards.

One could reply that this is not necessarily a bad option. The jury could function even if jurors do not entertain their own individual standards. For instance, jurors could vote insincerely. Specifically, perhaps jurors should refrain from having their individual standards, but vote in accordance with these standards (e.g., vote as if they entertained their individual standards). This way, the jury would function properly while the jurors do not entertain their own individual standards. Call this the objection from insincerity. ${ }^{21}$

There could be contexts in which some types of insincerity can be epistemically permitted. Fleisher (2019), for instance, has argued that scientists can publicly endorse ideas that they do not fully believe. Even if they have a low degree of confidence in their own theories, they can make a significant contribution to the advancement of science. Similarly, it is understandable that lawyers sometimes defend their clients while thinking they are guilty. Part of their job is to make the best case for their client, and sincerity is not required for this.

In view of the foregoing, it seems plausible that, on some occasions, agents are epistemically permitted to be insincere. I do not challenge this. My contention is that (i)

21 The objection from insincerity is a natural option for those who endorse strong accounts of standard possession. In section 1, I said that an agent possesses epistemic standards $\mathrm{S}$ if $\mathrm{S}$ are the rules, models or assumptions he or she relies on to evaluate the evidence. This is a weak account of standard possession. Some philosophers might think that there are more conditions on possessing standards, like fully supporting them. Relative to this stronger account of standard possession, we can see how juries can be perfectly functional without being sincere. All jurors need to do is to reduce their degree of support in the standards they use to evaluate the evidence. This way, they stop possessing their standards (because they do not fully support them anymore), but the jury is still perfectly functional (because jurors still process the evidence with these standards). I acknowledge that, relative to a strong interpretation of standard possession, this escape route is available to defenders of the Immodesty requirement. But as I have said earlier, I am here concerned with a weak interpretation of standard possession. 
insincerity is not always an available option, and (ii) even when being insincere is part of one's options, one sometimes fall under an obligation to be sincere.

In order to lend support to (i), I'll first make some brief remarks on familiar problems in ethics. They will help us see in what sense insincere voting is not always an option.

Suppose a trolley is moving towards five people. Anna stands next to a lever. She could pull the lever and divert the trolley onto the sidetrack, where it will kill 2 people. So, Anna has two options. First, she could do nothing and let five people die, and second, she could pull the lever and kill two people. However, one could suggest that Anna has more options. One could say: "Anna could alert the people on the tracks. If they hear her, they will move, and everybody will be saved!" However, this option is not always available. Perhaps Anna is mute, or perhaps the agents are tied to the track, and so forth. So, there will be cases in which, given the facts of the situation, Anna only has the two options mentioned above.

In a similar spirit, agents do not always have the option to vote insincerely. For instance, most courts expect jurors to be sincere, and give explicit instructions to jurors on sincerity. Such instructions could restrict the range of options available to jurors (e.g., they exclude insincerity). Now, you might objects that, even if jurors are asked to be sincere, they could lie and vote insincerely. However, some institutions could go a step further and make sure that there is no leeway between beliefs and votes. Consider the following case:

Implant. Carole is part of a special type of jury. All the jurors received a brain implant. At the end of the trial, Carol's implant records her beliefs that result from her evidence and standards. So if, at the end of the trial, her evidence and standards leads her to believing that Smith is guilty, it records "Smith is guilty." The implants communicate with each other and determine the jury's verdict. That is, rather than being a consequence of jurors casting their votes, the jury's verdict follows from the beliefs recorded by all the implants. This way, the verdict is guaranteed to be sincere.

In Implant, the institution doesn't let Carole vote insincerely. The collective verdict results directly from her beliefs, and so she can't vote in a way that conflicts with her beliefs. Given the facts of the situation, she can't have standards X but vote in accordance with standards Y. This confirms (i): insincerity is not always an option. 
What about (ii)? In many collective contexts, sincerity is part of why we trust an institution. When reliable jurors vote in accordance with their evidence and standards, we can easily make sense of the verdict. This allow us to trust the institution and defer to its verdicts. However, insincerity could generate distrust, and undermine the jury's initial goal, namely, to improve collective reliability. Consider the following case:

Trial. Twelve jurors have to determine if the defendant is guilty. As it happens, given their evidence and standards, none of them believe that he is guilty (and the judge told them that, in such a case, they should vote for "the defendant is not guilty"). However, none of them vote in accordance with their individual standards. All the jurors end up voting, in accordance with different standards, for "the defendant is guilty." When asked if they are satisfied with the verdict, the jurors say: "Well, none of us thought he did it. But this doesn't matter, and we found him guilty."

Cases like Trial are problematic. Communities could easily distrust the jury's verdict if they came to learn that, while none of the jurors believe that the defendant is guilty, they unanimously voted for "the defendant is guilty." The verdict would not make sense to the community. Part of why we form juries and other institutions is to improve collective reliability. However, insincerity can, in some contexts, be an obstacle to collective reliability. If communities end up not trusting juries composed of insincere jurors, the purpose of these institutions is defeated. This suggests that, at least in contexts where insincerity leads to distrust, jurors fall under an obligation to be sincere.

To be clear: Insincerity doesn't always lead to distrust. As I have said at the beginning of this section, lawyers sometimes defend their clients while believing they are guilty. We know full well this happens. This doesn't necessarily lead us to distrust legal proceedings Perhaps we merely expect lawyers to make the best possible case for their

clients. My point is merely that, in some contexts, insincerity can lead to distrust. For instance, we could easily distrust insincere members of a jury. On such occasions, agents can fall under an epistemic obligation to be sincere.

\section{Discussion: Ideal and Non-Ideal Epistemic Norms}

I have argued that non-ideal agents are sometimes permitted to be modest. However, I have left it open whether ideal agents should be immodest. In this section, I 
give the beginning of an answer to the question of why some epistemic norms might apply to ideal agents, but not to non-ideal agents. Specifically, I argue that there could be leeway between epistemic norms for ideal and non-ideal agents, and that there is no obvious reason why we should approximate ideal epistemic norms.

Some philosophers think that there is some sort of connection between ideal and non-ideal theories. A popular suggestion is that non-ideal norms consist in an approximation of ideals. ${ }^{22}$ According to such a view, we ought to approximate ideal epistemic figures to a certain degree. Typically, it is assumed that ideal epistemic figures are fully coherent, have an excellent ratio of true to false beliefs, reason perfectly, have unlimited cognitive capacities, and so forth. ${ }^{23}$

If this view concerning the approximation of ideals is right, it is unclear why nonideal agents can be modest while ideal agents cannot. Suppose ideal agents are immodest (say, because modesty is incoherent, and coherence is part of the epistemic ideal). Then, why not think that we ought to approximate the ideal epistemic figures, and fall under an obligation to be immodest? ${ }^{24}$

It is still unclear why agents like us, who cannot reach the epistemic ideal due to various (legitimate) constraints, should approximate it. Approximations claims have failed in other fields, and we have good reason to think that the lesson also applies in epistemology.

22 Staffel (2017) calls such a view the Imitation Thesis. Smithies (2015) endorses a similar view. See also Christensen (2004, chap. 6), Morton (2012, chap. 1), Pasnau (2013) or Talbott (2016, sec. 6.1.A) for discussion in various contexts.

23 See Christensen (2004, chap. 6), DiPaolo (2018), Earman (1992, 56), Paul and Quiggin (2018), Smithies (2015), Staffel (2017; forthcoming), and Talbott (2016, sec. 6.1.A) on the recourse to epistemic ideals. De Bona and Staffel (2018) argue that non-ideal agents should approximate some ideal coherence requirements, but this is compatible with thinking that non-ideal agents should not approximate all the ideal epistemic norms. In general, it is unclear what counts as an "ideal." See, for instance, Gaus (2016, chaps. 1-2) on this issue. Still, most philosophers agree upon some examples of ideal and non-ideal epistemic theories. For example, Bayesian epistemology (Joyce 1998; Pettigrew 2016) is often thought of as an idealized theory, whereas theories of bounded cognition and heuristics (Gigerenzer and Selten 2002; Kahneman 2003; Todd and Gigerenzer 2000) are often thought of as non-ideal theories.

24 It should be noted that it is not clear what "approximating an ideal" means. Suppose an ideal is defined in terms of the optimal value of some variables $x_{1}, x_{2}, \ldots, x_{n}$. Then, approximating the ideal can refer to getting as close as possible to the optimal values of $\mathrm{x}_{1}, \mathrm{x}_{2}, \ldots, \mathrm{x}_{\mathrm{n}}$. However, suppose an ideal is defined in terms of the features or states of affairs of an ideal world. Then, approximating the ideal can refer to meeting as many features of the ideal world as possible. These interpretations of approximation claims can conflict with each other. 
Consider the General Theory of the Second Best, a formal contribution to the field of utility (or welfare) optimization. The Theory analyzes the relationship between two optima: an optimal option relative to minimal constraints (the first-best option) and an optimal option relative to a set of additional constraints (the second-best option). As Lipsey and Lancaster say:

Perhaps the best way to approach the problem of defining the scope of the theory of second best is to consider the role of constraints in economic theory.... in the theory of the Paretian optimum, certain constraints are assumed to be operative and the conditions necessary for the maximization of some function subject to these constraints are examined. In the theory of second best there is admitted at least one constraint additional to the ones existing in Paretian optimum theory and it is in the nature of this constraint that it prevents the satisfaction of at least one of the Paretian optimum conditions. (Lipsey and Lancaster 1956, 12)

The General Theory of the Second Best is well known for suggesting that secondbest options are not a mere approximation of first-best options. The formal result relies on an application of the Lagrange multiplier method, which is used for finding a function's optima subject to some constraints. For present purposes, there is no need to be that specific. Here is a simple example. Suppose that, in the ideal market, there are no tariffs, because free markets optimize production. Now, suppose that nearly every country applies tariffs, but one country decides to adopt a free trade policy. There is a sense in which this action brings the world closer to the ideal of a free market. But does this action improve the global production? Not necessarily. In view of the global allocation of the resources, this action can be suboptimal. (Ozga 1955, 499) As Lipsey and Lancaster note:

[assume] that all commodities are, in consumption, rigidly complementary, so that their production either increases or decreases simultaneously... [then] in a three country world with tariffs all around, one country may adopt a policy of free trade and, as a result, the world production of all commodities may decrease. (Lipsey and Lancaster 1956, 14)

So, the first-best scenario involves free trade for all countries, but the second-best scenario can involve tariffs in every country. A country adopting a free trade policy would approximate the ideal world (e.g., meet more of the economic relationships defining the ideal world), but such a policy can nevertheless be suboptimal. 
Wiens have noted that this general lesson could also apply in other normative disciplines. He says:

The theory of second best is more general than is conventionally thought. As economists recognized from the start, the original theorem is not about economic theory and welfare policy per se but is instead about mathematical optimization in general.... Once we distinguish between the mathematical model and associated theorem on the one hand and the familiar economic interpretation of the model on the other, we clear the way for developing novel applications of the theorem. (Wiens forthcoming, 2)

In other words, the formal result underlying the Theory can be interpreted in many different ways, including epistemological ones. So, those who think that we ought to approximate ideal epistemic figures need to tell us why second-best problems do not arise in epistemology. A priori, there is no reason to think second-best problems cannot arise for epistemic norms. ${ }^{25}$

Another argument against the approximation of ideals has to do with the role of compensatory mechanisms in non-ideal scenarios. Ideal theory doesn't say much about how to compensate for our mistakes or imperfections, because agents in ideal worlds are perfect. This is why, for instance, ideal political theories often have little to say about just war. There are no wars in perfect political communities. The doctrine of just war is closely related to non-ideal theories, and is meant to compensate for the imperfections of political interactions. ${ }^{26}$

Compensatory mechanisms can explain why we should not always approximate ideals. Suppose that the ideal world has the following two attributes: (i) people never get sick and (ii) there are no hospitals. This makes sense, because hospitals are useless if people never get sick. Now, suppose that such an ideal world is unavailable, but that such worlds are available:

Option 1. (i-) some people get sick and (ii) there are no hospitals.

Option 2. (i-) some people get sick and (ii-) there are hospitals.

25 Wiens (forthcoming, sec. 3) also specifies the conditions in which second-best problems can be observed.

26 See, e.g., Walzer's (2015) afterword, where he discusses just wars and nonviolent ways to resolve military conflicts. 
Surely, if people get sick in this world, we want hospitals in this world. So, Option 2 is more valuable than Option 1. However, while Option 1 and the ideal world have one attribute in common (there are no hospitals), Option 2 and the ideal world have no attribute in common. As we can see, it would be absurd to claim that Option 1 is the best available option just because it is a better approximation of the ideal world. ${ }^{27}$ This is explained by the fact that, in non-ideal worlds, we need to compensate for our imperfections: in worlds where agents get sick, it is optimal for them to have recourse to compensatory mechanisms such as hospitals.

In a similar spirit, the "modest" division of epistemic labour in social institutions like juries could be a compensatory mechanism for agents like us. Suppose ideal agents have infinite cognitive capacities. So, internalizing epistemic standards cannot be cognitively demanding to them. By way of contrast, we are non-ideal agents with limited cognitive capacities, and internalizing some epistemic standards can be demanding to us. Forming juries and other social institutions can compensate for our imperfections: by working together, we compensate for our limited cognitive capacities. This even leads us, on some occasions, to trust these institutions more than we trust ourselves - that is, we sometimes take the institutional standards to be more reliable than our own individual standards. And this could explain why modesty is epistemically permitted for agents like us, but not for ideal agents.

These brief remarks do not prove out of doubt that approximation claims are false. But they give us a sense of why there could be some independence between ideal and nonideal epistemic norms. In other words, it is a live possibility that non-ideal epistemic norms do not merely consist in an approximation of ideal ones.

\section{Conclusion}

Many philosophers think that immodesty is epistemically required of agents. I have argued that modesty is epistemically permitted in some social contexts. I have focused on social contexts where agents with limited cognitive capacities cooperate with each other

27 Assuming, of course, that approximation is interpreted in terms of shared features. See footnote 24 . 
(like juries). I have also provided a tentative explanation of why approximating putative ideal epistemic norms (like Immodesty) might be suboptimal for agents like us.

Acknowledgements: This research was supported by the Social Sciences and Humanities Research Council (grant \#756-2019-0133). I warmly thank Aude Bandini, Ulf Hlobil, Sophie Horowitz, Daniel Laurier, Han Li, Éliot Litalien, Rémi Tison and Eric Wiland for helpful comments on this project.

\section{Bibliography}

Belot, Gordon. 2013. "Bayesian Orgulity." Philosophy of Science 80 (4): 483-503. https://doi.org/10.1086/673249.

Bommarito, Nicolas. 2018. "Modesty and Humility." In Stanford Encyclopedia of Philosophy, edited by Edward N. Zalta. https://plato.stanford.edu/archives/win2018/entries/modesty-humility/.

Broome, John. 2013. Rationality through Reasoning. Oxford: John Wiley \& Sons.

Buchak, Lara, and Philip Pettit. 2015. "The Case of Group Agents." Edited by Iwao Hirose and Andrew Reisner. Weighing and Reasoning: Themes from the Philosophy of John Broome, 207-31.

Chislenko, Eugene. 2014. "Moore's Paradox and Akratic Belief." Philosophy and Phenomenological Research. https://doi.org/10.1111/phpr.12127.

Christensen, David. 2004. Putting Logic in Its Place. Oxford: Oxford University Press.

—. 2013. "Epistemic Modesty Defended." In The Epistemology of Disagreement: New Essays, edited by David Christensen and Jennifer Lackey. Oxford: Oxford University Press.

Clarke, Roger. 2013. "Belief Is Credence One (in Context).” Philosopher's Imprint 13 (11): $1-18$.

Coates, Allen. 2012. "Rational Epistemic Akrasia." American Philosophical Quarterly 48 (2): 113-24.

Condorcet, Nicolas de. 1976. "Essay on the Application of Mathematics to the Theory of Decision-Making.” In Condorcet: Selected Writings. Indianapolis: Bobbs-Merrill.

Daoust, Marc-Kevin. 2019. “One Standard To Rule Them All?” Ratio 31 (1): 12-21.

Daoust, Marc-Kevin and David Montminy. "Immodesty and Permissivism." Unpublished Manuscript 
De Bona, Glauber, and Julia Staffel. 2018. "Why Be (Approximately) Coherent?" Analysis, 1-11. https://doi.org/10.1093/analys/anx159.

Demey, Lorenz. 2013. "Contemporary Epistemic Logic and the Lockean Thesis." Foundations of Science 18 (4): 599-610.

Dietrich, Franz, and Christian List. 2004. "A Model of Jury Decisions Where All Jurors Have the Same Evidence.” Synthese 142 (2): 175-202.

Dietrich, Franz, and Kai Spiekermann. 2013. "Epistemic Democracy With Defensible Premises." Economics \& Philosophy 29 (1): 87-120.

DiPaolo, Joshua. 2018. "Second Best Epistemology: Fallibility and Normativity." Philosophical Studies, 1-24. https://doi.org/10.1007/s11098-018-1110-y.

Earman, John. 1992. Bayes or Bust? A Critical Examination of Bayesian Confirmation Theory. Cambridge (MA): MIT Press.

Elga, Adam. 2010. "How to Disagree about How to Disagree." In Disagreement, edited by Ted Warfield and Richard Feldman. Oxford: Oxford University Press.

Estlund, David M. 1994. "Opinion Leaders, Independence, and Condorcet's Jury Theorem." Theory and Decision 36 (2): 131-162.

Fleisher, Will. 2019. "Endorsement and Assertion." Noûs. https://doi.org/10.1111/nous.12315.

Foley, Richard. 2009. "Beliefs, Degrees of Belief, and the Lockean Thesis." In Degrees of Belief, 37-47. Springer.

Gaus, Gerald. 2016. The Tyranny of the Ideal: Justice in a Diverse Society. Princeton and Oxford: Princeton University Press.

Gigerenzer, Gerd, and Reinhard Selten. 2002. Bounded Rationality: The Adaptive Toolbox. Cambridge (MA): MIT press.

Greco, Daniel. 2014. “A Puzzle about Epistemic Akrasia.” Philosophical Studies 167 (2): 201-219.

Hájek, Alan. 2007. "My Philosophical Position Says 'p' and I Don’t Believe 'p."' In Moore's Paradox: New Essays on Belief, Rationality, and the First Person, edited by Mitchell Green and Michael Williams, 217-31. Oxford: Oxford University Press.

Hedden, Brian. 2015. "A Defense of Objectivism about Evidential Support." Canadian Journal of Philosophy 45 (5-6): 716-743.

Horowitz, Sophie. 2014a. "Epistemic Akrasia." Noûs 48 (4): 718-744.

—. 2014b. "Immoderately Rational.” Philosophical Studies 167 (1): 41-56.

Huemer, Michael. 2007. "Moore's Paradox and the Norm of Belief." In Themes from GE Moore, edited by Susana Nucceteli and Gary Seays, 142-157. New York: Oxford University Press. 
Jackson, Elizabeth. forthcoming. "A Defense of Intrapersonal Belief Permissivism." Episteme.

Joyce, James M. 1998. “A Nonpragmatic Vindication of Probabilism.” Philosophy of Science 65 (4): 575-603.

Kahneman, Daniel. 2003. "Maps of Bounded Rationality: Psychology for Behavioral Economics." American Economic Review 93 (5): 1449-1475.

Kiesewetter, Benjamin. 2016. "You Ought to $\phi$ Only If You May Believe That You Ought to $\phi . " \quad T h e$ Philosophical Quarterly $66 \quad$ (265): 760-82. https://doi.org/10.1093/pq/pqw012.

Lasonen-Aarnio, Maria. 2014. "Higher-Order Evidence and the Limits of Defeat." Philosophy and Phenomenological Research 88 (2): 314-345.

- 2015. "New Rational Reflection and Internalism about Rationality." Oxford Studies in Epistemology 5: 145-171.

—. 2018. "Enkrasia or Evidentialism? Learning to Love Mismatch." Philosophical Studies. https://doi.org/10.1007/s11098-018-1196-2.

Leitgeb, Hannes. 2014a. "The Review Paradox: On the Diachronic Costs of Not Closing Rational Belief under Conjunction." Noûs 48 (4): 781-793.

_. 2014b. "The Stability Theory of Belief." Philosophical Review 123 (2): 131-171.

Lewis, David. 1971. "Immodest Inductive Methods." Philosophy of Science 38 (1): 54-63.

Li, Han. 2016. "The Trouble with Having Standards." Philosophical Studies, 1-21. https://doi.org/10.1007/s11098-018-1055-1.

- 2017. "A Theory of Epistemic Supererogation." Erkenntnis, 1-19. https://doi.org/10.1007/s10670-017-9893-3.

Lipsey, Richard G., and Kelvin Lancaster. 1956. "The General Theory of Second Best." The Review of Economic Studies 24 (1): 11-32.

Littlejohn, Clayton. 2015. "Stop Making Sense? On a Puzzle about Rationality." Philosophy and Phenomenological Research. https://doi.org/10.1111/phpr.12271.

Mayo-Wilson, Conor, and Gregory Wheeler. 2016. "Scoring Imprecise Credences: A Mildly Immodest Proposal." Philosophy and Phenomenological Research. http://onlinelibrary.wiley.com/doi/10.1111/phpr.12256/full.

Morton, Adam. 2012. Bounded Thinking: Intellectual Virtues for Limited Agents. Oxford: Oxford University Press.

Ozga, S. A. 1955. "An Essay in the Theory of Tariffs." Journal of Political Economy 63 (6): 489-99. https://doi.org/10.1086/257723.

Pasnau, Robert. 2013. "Epistemology Idealized." Mind 122 (488): 987-1021. https://doi.org/10.1093/mind/fzt093. 
Paul, L. A., and John Quiggin. 2018. "Real World Problems." Episteme, 1-20. https://doi.org/10.1017/epi.2018.28.

Pettigrew, Richard. 2016. Accuracy and the Laws of Credence. Oxford: Oxford University Press.

Roush, Sherrilyn. 2017. "Epistemic Self-Doubt.” In Stanford Encyclopedia of Philosophy, edited by Edward N. Zalta. https://plato.stanford.edu/archives/win2017/entries/epistemic-self-doubt/.

Schoenfield, Miriam. 2014. "Permission to Believe: Why Permissivism Is True and What It Tells Us about Irrelevant Influences on Belief." Noûs 48 (2): 193-218.

Smithies, Declan. 2012. "Moore's Paradox and the Accessibility of Justification." Philosophy and Phenomenological Research 85 (2): 273-300.

_. 2015. "Ideal Rationality and Logical Omniscience." Synthese 192 (9): 2769-93. https://doi.org/10.1007/s11229-015-0735-z.

Staffel, Julia. forthcoming. "Bayesian Norms and Non-Ideal Agents." In Routledge Handbook of the Philosophy Evidence, edited by Clayton Littlejohn and Maria Lasonen-Aarnio. Routledge. https://philpapers.org/rec/STABNA-2.

—. 2017. "Should I Pretend I'm Perfect?" Res Philosophica 94 (2): 301-24. https://doi.org/10.11612/resphil.1536.

Sturgeon, Scott. 2008. "Reason and the Grain of Belief." Noûs 42 (1): 139-165.

Talbott, William. 2016. "Bayesian Epistemology." In The Stanford Encyclopedia of Philosophy, edited by Edward N. Zalta. https://plato.stanford.edu/archives/win2016/entries/epistemology-bayesian/.

Titelbaum, Michael G. 2015. "Rationality's Fixed Point (or: In Defense of Right Reason)." Oxford Studies in Epistemology 5: 253-294.

Titelbaum, Michael G., and Matthew Kopec. forthcoming. "When Rational Reasoners Reason Differently." In Reasoning: Essays on Theoretical and Practical Thinking, edited by M Balcerak Jackson and B Balcerak Jackson. Oxford University Press.

Todd, Peter M., and Gerd Gigerenzer. 2000. "Précis of Simple Heuristics That Make Us Smart." Behavioral and Brain Sciences 23 (05): 727-741.

Walzer, Michael. 2015. Just and Unjust Wars: A Moral Argument with Historical Illustrations. New York: Basic books.

Weatherson, Brian. 2015. "For Bayesians, Rational Modesty Requires Imprecision." Ergo 2 (20): 529-45. https://doi.org/10.3998/ergo.12405314.0002.020.

Wiens, David. forthcoming. "The General Theory of Second Best Is More General Than You Think." Philosophers' Imprint. https://philpapers.org/rec/WIETGT.

Worsnip, Alex. 2018. "The Conflict of Evidence and Coherence." Philosophy and Phenomenological Research 46 (1): 3-44. https://doi.org/10.1111/phpr.12246. 